\title{
Electrophysiological Actions of VIP in Rat Somatosensory Cortex
}

\author{
FRANCIS M. SESSLER, ${ }^{1}$ STEVE M. GRADY, BARRY D. WATERHOUSE AND HYLAN C. MOISES* \\ Department of Physiology and Biophysics, Hahnemann University, Philadelphia, PA 19102-1192 \\ *Department of Physiology, University of Michigan, Medical School, Ann Arbor, MI 48109
}

Received 10 December 1990

\begin{abstract}
SESSLER, F. M., S. M. GRADY, B. D. WATERHOUSE AND H. C. MOISES. Electrophysiological actions of VIP in rat somatosensory cortex. PEPTIDES 12(4) 715-721, 1991. - Electrophysiological and biochemical studies suggest that VIP may exert a facilitating action in the neocortical local circuitry. In the present study, we examined the actions of VIP and VIP + norepinephrine (NE) on somatosensory cortical neuron responses to direct application of the putative transmitters acetylcholine (ACh) and gamma-aminobutyric acid (GABA). Spontaneous and transmitter-induced discharges of cortical neurons from halothane-anesthetized rats were monitored before, during and after VIP, NE and VIP + NE iontophoresis. In 57 VIP-sensitive cells tested, VIP application $(5-70 n A)$ increased $(n=18)$, decreased $(n=36)$ or had biphasic actions $(n=3)$ on background firing rate. In a group of 20 neurons tested for NE + VIP, the combined effect of both peptide and bioamine was predominantly (70\%) inhibitory. On the other hand, inhibitory and excitatory responses of cortical neurons to GABA (11 of 15 cases) and ACh (10 of 18 cases), respectively, were enhanced during VIP iontophoresis. Concomitant application of VIP and NE produced additive $(n=2)$ or more than additive $(n=3)$ enhancing effects on GABA inhibition. NE administration reversed or enhanced further VIP modulatory actions on ACh-induced excitation. These findings provide electrophysiological evidence that NE and VIP afferents may exert convergent influences on cortical neuronal responses to afferent synaptic inputs such that modulatory actions are anatomically focused within the cortex.
\end{abstract}

Vasoactive intestinal polypeptide Norepinephrine GABA Cortex Acetylcholine Neuromodulation

A number of findings suggest that vasoactive intestinal polypeptide (VIP) may play a role in neuronal transmission within the cerebral cortex (26). VIP is found in high concentration in this area (13), and is located primarily in bipolar neurons oriented perpendicular to the pial surface $(13,20)$. The peptide can be released in $\mathrm{C} \mathrm{Ca}^{++}$-dependent manner from synaptosomal preparations (8) and rat brain slices (2). VIP binding has been observed in cerebral cortex (29) and local application of VIP to individual cortical neurons produces both inhibitory and excitatory responses $(6,9,12,24)$. Additional biochemical studies have shown that VIP can alone or by synergistic interaction with norepinephrine (NE) increase cyclic-AMP (cAMP) levels in cerebrocortical tissue (15).

VIP-containing neurons constitute an intracortical peptidergic system which is oriented perpendicular to the tangential trajectory of NE-containing axons emanating from cell bodies in the brainstem nucleus locus coeruleus. It has been suggested $(18,20)$ that this unique anatomical arrangement may subserve a specific physiologic function whereby the potential heterosynaptic interaction of NE-VIP input on common target neurons could create conditions leading to enhancement of cAMP-mediated events. As a first step in assessing VIPergic influences on cerebrocortical synaptic transmission, we examined the interaction between microiontophoretically applied VIP and somatosensory cortical neuron responses to locally applied putative neurotransmitters, gamma-aminobutyric acid (GABA) and acetylcholine (ACh). A second goal of the study was to evaluate the effects of simultaneous application of NE and VIP on spontaneous and evoked cortical neuronal activity.

The results indicate that VIP produces predominantly facilitating effects on transmitter-induced responses of somatosensory cortical neurons. Simultaneous application of NE and VIP produces either additive or more than additive facilitating effects on somatosensory cortical neuronal responsiveness to GABA application. By contrast, NE administration reverses or enhances VIP modulatory effects on ACh-induced excitation. A preliminary report of this work has appeared previously (32).

\section{METHOD}

Male Long-Evans hooded rats, $250-350 \mathrm{~g}$, were anesthetized with halothane $(0.8-1.5 \%$ in oxygen), intubated and allowed to breathe spontaneously. Animals were fixed in a stereotaxic apparatus and body temperature was maintained at $37^{\circ} \mathrm{C}$ with a heating lamp. Portions of the calvarium and dura were removed to obtain access to the somatosensory cortex. The exposed brain tissue was covered with $2 \%$ agar in balanced salt solution.

The somatosensory cortex recording electrode was aimed: A-P $=0$ to $2 \mathrm{~mm} ; \mathrm{L}=3$ to $5 \mathrm{~mm}$, and 0 to $1.8 \mathrm{~mm}$ deep to pial surface (Paxinos et al., 1982). Five-barrel micropipets with 4-8

\footnotetext{
${ }^{1}$ Requests for reprints should be addressed to Dr. F. M. Sessler, Hahnemann University, Department of Physiology and Biophysics, M.S. 409, Broad and Vine Street, Philadelphia, PA 19102-1192.
} 
$\mu \mathrm{m}$ tips were used for drug application and single-unit recording. The center recording barrel of the pipet was filled with $4 \mathrm{M}$ $\mathrm{NaCl}$. One side barrel was filled with $3 \mathrm{M} \mathrm{NaCl}$ and used for automatic current balancing. The remaining side barrels contained drug solution as follows: $0.5 \mathrm{M}$ dl-norepinephrine $\mathrm{HCl}$, pH 4.5 (Sigma); 0.5 M GABA, pH 3.8 (Sigma); $1 \mathrm{M}$ acetylcholine chloride, $\mathrm{pH} 4.5$ (Sigma); $0.5-1 \mathrm{mM}$ VIP (in $0.1 \mathrm{M}$ $\mathrm{NaCl}$ or distilled water), pH 5.5 (a gift of Dr. S. I. Said of the University of Oklahoma Health Sciences Center, Oklahoma City). Control procedures for assessing potential current artifacts and vehicle $(\mathrm{NaCl})$ effects were carried out routinely. Extracellularly recorded action potentials were monitored using conventional methods.

Regularly spaced iontophoretic pulses of GABA or ACh (10-20-s duration; 5-50 nA) were applied to individual cells until stable agonist responses were obtained. Perievent histograms were then collected before, during and after VIP or VIP + NE iontophoresis. Agonist ejection currents were selected to induce approximately $40-50 \%$ of the response maxima. Putative transmitter responses were quantitated by comparing the average discharge rate of the neuron during transmitter application with the mean firing rate between drug pulses and expressing the difference as a percentage inhibition or excitation of baseline firing frequency.

Drug interactions were frequently conducted using iontophoretic doses of VIP which were subthreshold for causing changes in the baseline firing rate of recorded neurons. This procedure reduced the possibility that changes in cell responsiveness observed during VIP administration were due simply to an algebraic summation of ongoing excitatory or inhibitory VIP effects. All interactions between neurotransmitters were judged against criteria based on quantification of responses from histogram records $(27,31)$. Changes in responses to excitatory or inhibitory stimuli by VIP were assessed by comparing the discharge rate in identical epochs of baseline and drug-induced activity taken from control and VIP histograms. VIP was declared to have no significant differential effect on inhibitory or excitatory responses when the percentage of change in evoked versus spontaneous discharge was equivalent. A difference of at least $15 \%$ between percent of VIP-induced changes in evoked versus spontaneous activity was established as the criterion for declaring a differential effect (i.e., "augmentation," "enhancement'" or "antagonism") on evoked versus spontaneous discharge. "Augmentation" of an inhibitory response was declared when firing rate during the response epoch was depressed more by VIP application than was spontaneous discharge. Conversely, the interaction was defined as "antagonistic" when spontaneous discharge was depressed more by VIP than activity occurring during the inhibitory response period.

"Enhancement" of excitatory responses was declared when evoked spiking was increased above control levels relative to no change or suppression of background firing or when activity during evoked excitation was suppressed by VIP but to a lesser extent than was background firing. The interaction was termed "antagonistic" when the excitatory response was more suppressed than spontaneous firing during VIP iontophoresis. These criteria for quantitative evaluation of VIP interactions with neuronal responses to synaptic stimuli have been employed previously to asses NE actions in cerebral cortex (30), cerebellum $(19,28)$ and hypothalamus $(4,27)$.

\section{RESULTS}

Of 140 neurons recorded from the somatosensory cortex, 65 (46\%) were sensitive to VIP application. The majority of these
TABLE 1

VIP AND VIP + NE EFFECTS ON SPONTANEOUS FIRING ACTIVITY OF SOMATOSENSORY CORTICAL NEURONS

\begin{tabular}{lcccc}
\hline & N & Inhibition & Biphasic & Excitation \\
\hline $\begin{array}{l}\text { VIP effects on } \\
\text { spontaneous activity (SA) }\end{array}$ & 57 & $63 \%$ & $5 \%$ & $32 \%$ \\
& & $\begin{array}{c}\text { Enhanced } \\
\text { Inhibition } \\
\text { (or reversal) } \\
73 \%\end{array}$ & $\begin{array}{c}\text { Enhanced } \\
\text { Excitation } \\
\text { (or reversal) } \\
\text { NE effects on } \\
\text { VIP-induced inhibition }\end{array}$ \\
$\begin{array}{l}\text { NE effects on } \\
\text { VIP-induced excitation }\end{array}$ & 11 & $67 \%$ & $33 \%$ \\
\hline
\end{tabular}

$(\mathrm{n}=56,86 \%)$ were found in cortical layers between $700-1600$ $\mu \mathrm{m}$ deep from the pial surface. VIP-induced changes in cortical unit responsiveness to $\mathrm{ACh}$ and GABA application were observed in cells within this same region.

\section{Effects of VIP on Cortical Neuron Spontaneous Discharge}

Only spontaneously active VIP-responsive somatosensory cortical neurons $(\mathrm{N}=57)$ were used in this study. Their frequency of discharge ranged from 0.5 to $26.7 \mathrm{~Hz}$ (mean $=7.1 \pm 0.7 \mathrm{~Hz}$; mean $\pm \mathrm{SE}$ ). No significant relation could be established between cell depth, spontaneous firing frequency and response to VIP.

In 36 of 57 cells exhibiting spontaneous discharge, continuous iontophoretic application of VIP (5-70 nA) reduced firing rate by $27.1 \pm 3.2 \%$ (mean \pm SEM) from control. In 18 other cells, spontaneous activity was increased an average of $42.5 \pm 10.1 \%$ during VIP application. In three remaining cells, VIP induced biphasic effects on baseline activity (see Table 1).

The combined effects of NE + VIP application were examined in 20 VIP-sensitive cells ( 9 excited and 11 inhibited by VIP). In $70 \%$ of these cases $(n=14), N E+$ VIP application produced depression of somatosensory cortical neuron discharge even though VIP alone evoked excitation in 6 of these cells. In most of these cases, NE was applied at doses that alone produced little or no change in spontaneous firing. In 6 other cases, the combination of NE + VIP produced: 1) excitation like that observed with VIP alone $(n=3)$ or 2$)$ reversal of VIP-induced suppression of spontaneous activity $(n=3)$ (see Table 1 ).

Overall, these results show that VIP alone has facilitatory and inhibitory actions on background firing; however, the combined effect of NE + VIP is predominantly inhibitory. Thus, as previously reported by Ferron et al. (6), NE can convert VIP excitation into inhibition.

\section{Effects of VIP on Cortical Neuronal Responses to GABA}

Pulsatile applications of GABA (10-s duration, every $40 \mathrm{~s}$ ) produced consistent decreases in somatosensory cortical cell discharge. Interactions between VIP and neuronal responses to microiontophoretically applied GABA were analyzed in 15 cells. In the majority of the cases $(n=11,73 \%)$, inhibitory responses to GABA were markedly enhanced during VIP iontophoresis (see Table 2). An example of this effect is shown in Fig. 1A. In this neuron, administration of the peptide $(20 \mathrm{nA})$ produced a reduction in discharge rate during the GABA response period from 4.26 (control) to 1.42 (VIP) spikes/s, but little change in the background firing rate of the cell. This differential action of 



A2
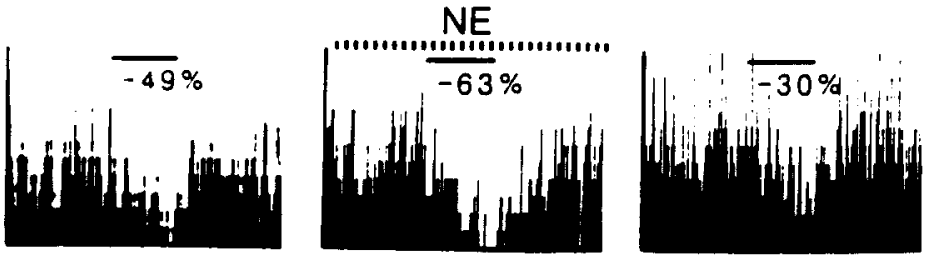

B2
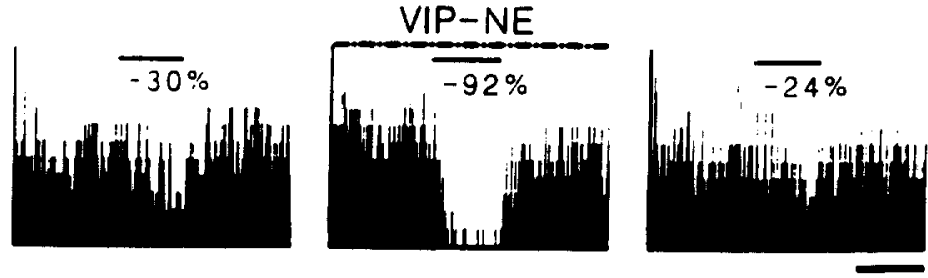

$\mathrm{C} 2$

FIG. 1. VIP-mediated enhancement of GABA-induced inhibition and interaction with NE-mediated augmentation of GABA inhibition of cortical neurons. Continuous ratemeter (top: $\mathrm{A} 1, \mathrm{~B} 1, \mathrm{C} 1$ ) and histogram (bottom, A2,B2,C2) show the responses of a cortical neuron to iontophoretic pulses (30 $\mathrm{nA}$; every $40 \mathrm{~s}$ ) of GABA (solid bars) before, during and after continuous microiontophoresis (broken bars) application of: VIP $20 \mathrm{nA}$ (A); NE $15 \mathrm{nA}$ (B); and VIP $20 \mathrm{nA}+$ NE $15 \mathrm{nA}$ (C). Histograms sum activity during 5 consecutive GABA applications. (A2) Constant application of VIP markedly enhanced the GABA-mediated inhibition from $-35 \%$ to $-79 \%$, without affecting the background activity of the cell, yielding a $126 \%$ increase of the inhibition relative to control. (B2) Administration of NE $15 \mathrm{nA}$ augmented the GABA-mediated inhibition from $-49 \%$ to $-63 \%$, yielding a $28 \%$ increase of the inhibition relative to control. (C2) Simultaneous administration of VIP and NE augmented the GABA inhibition from $-30 \%$ to $-92 \%$, yielding a $206 \%$ increase of the inhibition relative to control period. Calibration: vertical, 5 spikes; horizontal, $20 \mathrm{~s}$ (top), $10 \mathrm{~s}$ (bottom).

VIP on transmitter-induced versus spontaneous activity yielded a $125 \%$ enhancement (from $35 \%$ to $79 \%$ ) of the GABA response relative to the control condition. Recovery to the control level of response was observed a few minutes after cessation of VIP administration.
A summary of the results of similar quantitative analyses for all 15 neurons examined (open squares) is presented in Fig. 2. The majority $(73 \%)$ of data points lie well above the 45 degree "equivalence" line, indicating cases in which firing rate during the GABA-induced inhibitory period was depressed more during 
TABLE 2

VIP EFFECTS ON GABA- AND ACh-EVOKED NEURONAL RESPONSES

\begin{tabular}{lcccc}
\hline & N Antagonism & $\begin{array}{c}\text { No Differential } \\
\text { Effect }\end{array}$ & Facilitation \\
\hline $\begin{array}{l}\text { VIP effects on } \\
\begin{array}{l}\text { GABA-evoked inhibition } \\
\text { VIP effects on } \\
\text { ACh-evoked excitation }\end{array}\end{array}$ & 15 & $0 \%$ & $27 \%$ & $73 \%$ \\
\hline
\end{tabular}

VIP iontophoresis than was spontaneous discharge. In 4 of 15 cases $(27 \%)$, spontaneous activity and discharge rate during the GABA response period were affected to an equivalent extent during VIP administration (points plotted closest to the 45 degree "equivalence" line). Overall, this distribution of points indicates a trend toward a VIPergic facilitation of GABA inhibitory action.

\section{Effects of VIP on Cortical Neuronal Responses to ACh}

Pulsatile iontophoretic application of ACh (10-20-s duration, every 40-50 s) produced consistent increases in somatosensory cortical cell discharge as illustrated in Fig. 3. Interactions between VIP and cortical neuronal responses to microiontophoretically applied ACh were analyzed in 18 cells (see Table 2). In 10 of these cells (56\%), VIP application enhanced ACh-induced discharge relative to spontaneous firing. Figure 3 illustrates one

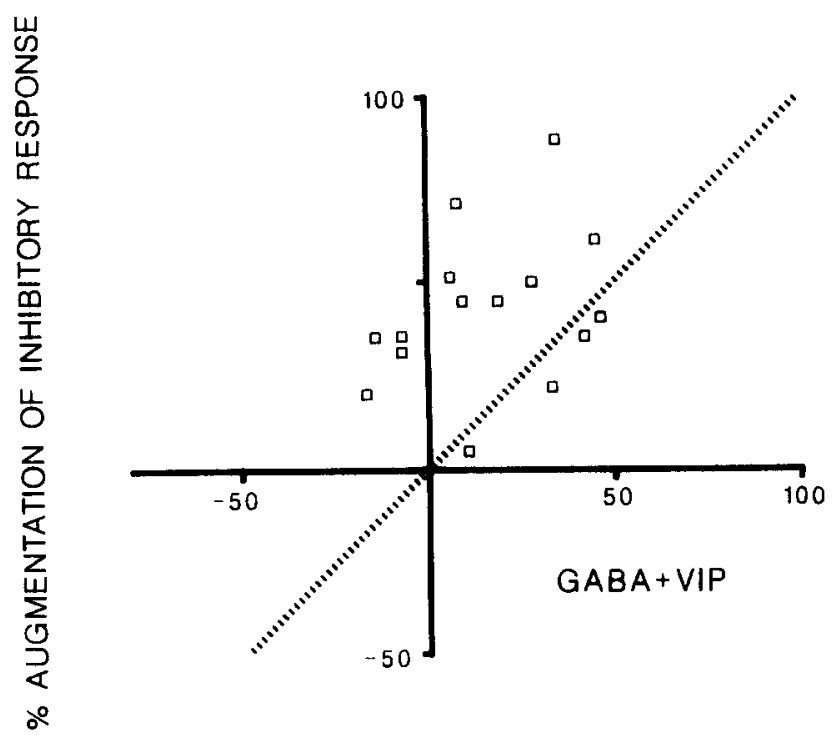

\section{\% SUPPRESSION OF SPONTANEOUS ACTIVITY}

FIG. 2. Graphic summary of VIP potentiating effects on GABA-mediated inhibition of somatosensory cortical neurons. Each plotted point indicates the VIP-induced change in GABA-mediated (open square) inhibition versus spontaneous discharge for one cortical neuron as determined from quantitative analysis of drug response perievent histograms. The dotted 45 degree line indicates the prediction of an equivalent effect of VIP on spontaneous activity and firing rate during the inhibitory response period. Data points lying above the "equivalence line" represent cases where GABA-induced inhibition was augmented relative to changes in background firing. neuron whose responses to $\mathrm{ACh}$ administration were increased above control levels during an iontophoretic dose of VIP (30-50 nA) which caused little change in the background activity of the cell. Quantitative assessment of the VIP-induced changes in evoked versus spontaneous firing frequency revealed an absolute increase (38\%) in the ACh response from 8.2 (control) to 11.3 (VIP) spikes/s, whereas spontaneous activity was decreased from 1.1 (control) to 0.9 (VIP) spikes/s. Recovery was observed a few minutes after cessation of VIP iontophoresis.

In 4 cells, ACh-induced excitation was antagonized during local administration of VIP, and in 4 other cases spontaneous and ACh-evoked discharge were equally affected by VIP, yielding no net differential change in cholinergic response (see Table 2).

\section{$V I P+N E$ Effects on Cortical Neuronal Responses to $A C h$ and $G A B A$}

The effects of VIP + NE on cortical neuronal responses to GABA $(n=6)$ or ACh $(n=14)$ were examined in 20 cells. Simultaneous application of VIP and NE enhanced GABA-induced inhibition in 5 of 6 cells tested. In 2 of these cases, VIP + NE-mediated augmentation of GABA responses was equivalent to algebraic summation of the actions of VIP and NE alone on GABA responses. In the 3 other neurons tested, the resulting augmentation was equivalent to a more than additive effect of the monoamine and peptide on GABA depressant actions (see Table 3). Figure 1 illustrates one such case where VIP alone, $\mathrm{NE}$ alone and VIP + NE produced $125 \%$ (from $35 \%$ to $79 \%$ ), $28 \%$ (from $49 \%$ to $63 \%$ ) and $206 \%$ (from $30 \%$ to $92 \%$ ) augmentation of GABA responses, respectively.

By contrast, continuous iontophoretic administration of VIP + NE during pulsatile ACh application $(n=14)$ produced varied effects which were not predictable on the basis of an algebraic summation of the actions of NE and VIP alone on AChinduced excitation. For example, Fig. 4 illustrates a case where VIP alone and NE alone produced $156 \%$ (41\% to $105 \%$ ) and $122 \%$ (from $37 \%$ to $82 \%$ ) increases in ACh-evoked responses, respectively. However, in the same cell simultaneous application of VIP + NE produced a $41 \%$ (from $37 \%$ to $22 \%$ ) reduction in ACh-induced excitation relative to background firing (see Table 3).

Overall, we observed that NE application further augmented VIP-mediated enhancement of GABA-induced suppression of cortical cell discharge, yet VIP actions on ACh-induced excitation were either enhanced or reversed by NE administration.

\section{DISCUSSION}

Although the anatomic organization of VIP-containing neurons in the neocortex has been well studied $(16,17,21)$, the effects of VIP on cortical neuron excitability have not yet been examined in great detail. In this study, we employed several experimental strategies to characterize the effects of VIP on neuronal responsiveness within the rat somatosensory cortex. Iontophoretic application of VIP produced both excitatory and inhibitory effects on the firing rate of spontaneously active cortical neurons. The direction of these effects was independent of cortical depth and spontaneous firing frequency of the neurons tested. Concomitant application of NE increased VIP's inhibitory action or, conversely, reversed VIP's excitatory effect on spontaneous discharge. Synergistic interactions between this monoamine and VIP have been reported previously by Ferron et al. (6). In addition, low doses of iontophoretically applied VIP were capable of modulating both excitatory and inhibitory responses 

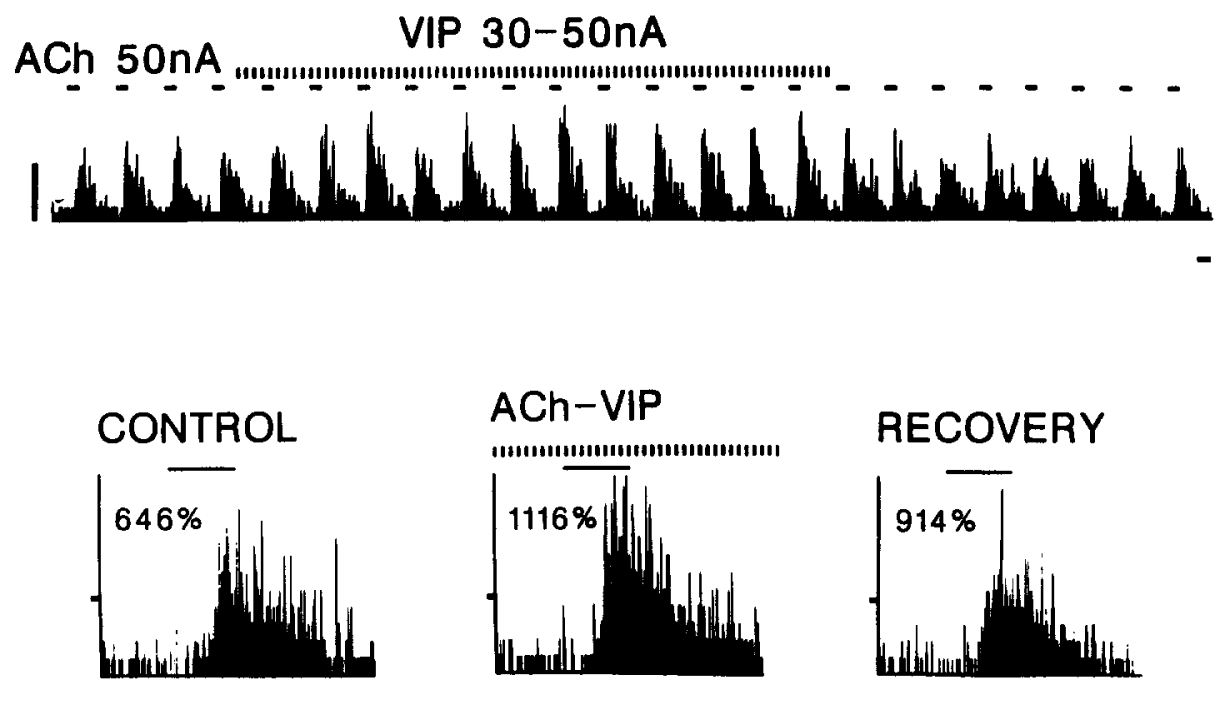

FIG. 3. VIP enhancement of ACh-induced excitation. Continuous ratemeter (top) and corresponding histogram (bottom) (sum of $4 \mathrm{ACh}$ applications) records illustrate the response of a somatosensory cortical neuron to iontophoretic pulses ( $50 \mathrm{nA}$; every $40 \mathrm{~s}$ ) of $\mathrm{ACh}$ before, during and after continuous microiontophoretic application of VIP (30-50 nA). VIP administration increased the ACh-induced excitation by $72 \%$, from $646 \%$ to $1116 \%$. Calibration: Horizontal, $10 \mathrm{~s}$; vertical, 10 (top), 5 (bottom) spikes.

of somatosensory cortical neurons to iontophoretic application of $\mathrm{ACh}$ and GABA, respectively. We also observed that $\mathrm{NE}$ in combination with VIP could enhance peptide-induced changes in neuronal excitability.

It is worth noting that many cells responding to VIP in the present study were located in deep cortical layers (700-1600 $\mu \mathrm{m})$. VIP-responsive cells have been identified by others as pyramidal neurons $(6,12,24)$. Such cells have long apical dendrites which extend from layer V or III to layer I and thus are well positioned to receive convergent synaptic inputs from VIPergic and noradrenergic afferents (18). In addition, because of this unique arrangement $(13,18,20,21)$, VIP-containing neurons and NE-containing cortical afferents may directly influence and modulate the cortico-cortical and corticofugal outputs from targeted regions of the cortex.

\section{VIP Enhancement of Cortical Neuronal Responses to GABA}

The results presented here demonstrate that iontophoretically applied VIP can facilitate GABA-induced suppression of cortical neuronal discharge. An important characteristic of this potentiating action is that this effect does not appear to result from a simple summation of hyperpolarizing influences. As shown in
Fig. 1, changes in neuronal responsiveness to GABA were observed at ejection currents of VIP that had little direct effect on spontaneous discharge. Thus amplification of GABA responses by VIP can occur independently of direct inhibitory effects on spontaneous firing mechanisms. We have recently observed in pilot experiments that iontophoretically applied VIP can also potentiate ( 7 of 8 cases) responses of cortical cells to synaptically mediated inhibition.

In terms of what is known of VIP's cellular actions, it seems reasonable to suggest a link between the potentiating effect of VIP on inhibitory neuronal responses and its ability to stimulate intracellular production of cAMP. VIP has been shown to activate adenylate cyclase in each of the tissues that possess highaffinity VIP receptors $(23,26)$. Furthermore, cyclic AMP-mediated phosphorylation of a subunit of the GABA-A receptor has been proposed as a possible means of regulating the efficacy of GABA at central synapses (11). In this regard, VIP effects on GABA-induced neuronal responses are similar to those observed with other agents which elevate intracellular levels of cyclic AMP such as isoproterenol (beta agonist), 8-bromo cyclic AMP (membrane permeant analog of cyclic AMP), forskolin (direct activator of adenyl cyclase) and IBMX (phosphodiesterase inhibitor) (28)

TABLE 3

VIP + NE EFFECTS ON GABA- AND ACh-INDUCED NEURON RESPONSES

\begin{tabular}{lrcccc}
\hline & \multicolumn{2}{c}{$\begin{array}{c}\text { Facilitation } \\
\text { More Than } \\
\text { Additive }\end{array}$} & Additive & $\begin{array}{c}\text { More Than } \\
\text { Additive }\end{array}$ & Additive \\
\hline VIP + NE effects on & & & & & \\
GABA-induced inhibition & 6 & $50 \%$ & $33 \%$ & $17 \%$ & $0 \%$ \\
ACh-induced excitation & 14 & $29 \%$ & $0 \%$ & $64 \%$ & $7 \%$ \\
\hline
\end{tabular}



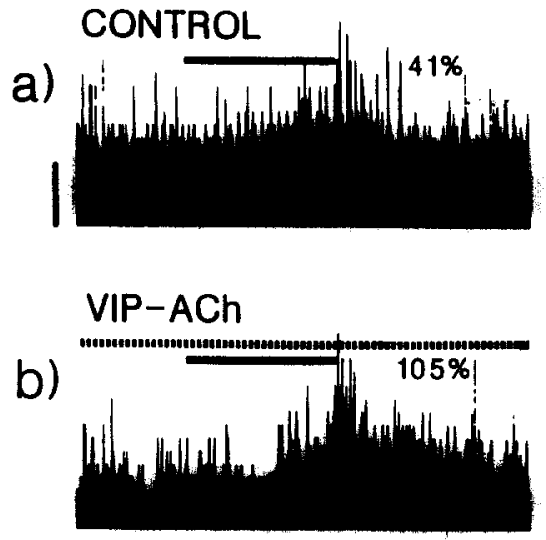

\section{RECOVERY}

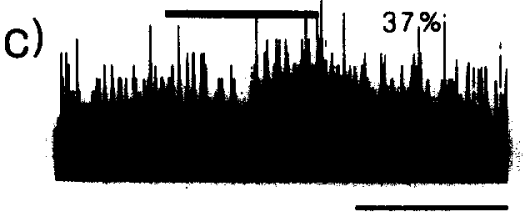

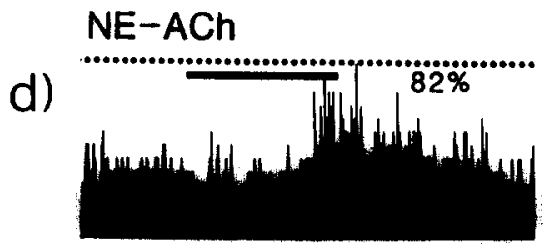
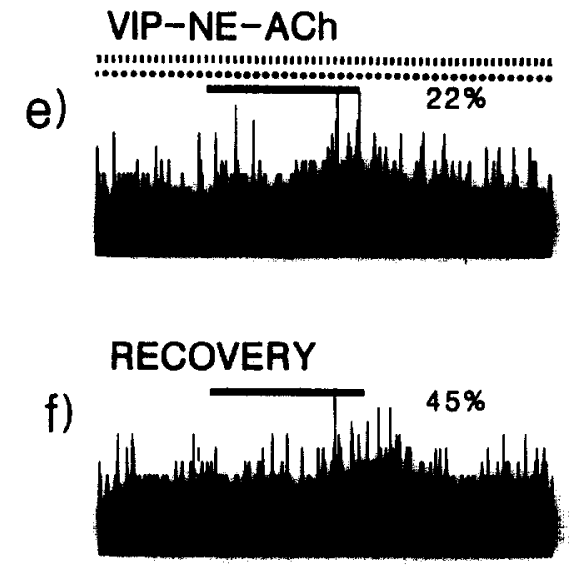

FIG. 4. VIP-mediated enhancement of ACh-induced excitation and interaction with NE-mediated augmentation of $\mathrm{ACh}$ excitation of cortical neurons. Histograms sum activity during 5 consecutive ACh (40 nA) applications. (a,b) Constant application of VIP (25 nA) markedly enhanced the AChmediated excitation from $41 \%$ to $105 \%$ by suppressing more the background discharges than the evoked activity (enhancement of signal to noise ratio). This action of VIP yielded a $156 \%$ increase of the excitation relative to control. (c,d) Administration of NE (10 nA) augmented the ACh-mediated excitation from $37 \%$ to $82 \%$, yielding a $122 \%$ increase of the response relative to control period. (e,f) Simultaneous administration of VIP and NE antagonized the ACh excitation from 37\% to $22 \%$, yielding a $41 \%$ decrease in ACh response. Calibration: vertical, 5 spikes; horizontal, 15 s.

When VIP and NE were applied simultaneously, they produced additive and in some cases more than additive enhancement of GABA-evoked inhibition. These alterations in GABAresponsiveness may be related to a combined action of VIP and $\mathrm{NE}$ affecting intracellular levels of cAMP. For example, the interaction between VIP and other drugs known to stimulate production of cAMP (e.g., dopamine, norepinephrine, isoproterenol, prostaglandin E1, adenosine) can produce additive (25) and in some case more than additive (15) increases of cAMP in brain tissue (25).

\section{VIP Modulation of Cortical Neuronal Excitatory Responses}

Iontophoretically applied VIP produced predominantly facilitatory $(56 \%)$ and in some cases antagonistic $(22 \%)$ effects on ACh-evoked discharges of cortical neurons. Results from other studies have shown that such VIPergic influences on $\mathrm{ACh}$ evoked responses are specific for cholinergic mechanisms (12).

More recent experimental evidence suggests that VIP may also exert its facilitating action on $\mathrm{ACh}$-induced excitation through a cAMP-dependent intracellular mechanism. In the hippocampus (14) and neocortex (7), intracellular increase of cAMP, or direct application of a membrane permeant analog of cAMP (14) has been shown to block accommodation of pyramidal cell discharge, thus resulting in a net increase in neuronal response to depolarizing stimuli. Since mechanisms responsible for blockade of accommodation are also sensitive to ACh (22), they could be a target for converging VIP $+\mathrm{ACh}$ influences on neuronal excitability.
The likelihood of a physiologically relevant VIP-ACh interaction is further supported by a report describing an intracortical cholinergic system with the same morphological characteristics as VIP neurons (5). Over $80 \%$ of the choline acetyltransferase (ChAT)-positive neurons described in that study also contained VIP. The fact that chronic atropine treatment causes a $75 \%$ increase in VIP receptors in cerebral cortex (1) also suggests a functional VIP-ACh interaction.

In many cases, application of NE potentiated VIP's actions on ACh-evoked excitatory responses. These effects were observed even if NE and VIP alone had opposite actions on cholinergic responses. In other cases, NE application antagonized VIP's effects on ACh responses. This antagonistic interaction was observed even when application of NE or VIP alone had facilitating effects on $\mathrm{ACh}$ responses (Fig. 4). While the present studies made no attempt to identify the mechanisms responsible for these mixed effects, the data suggest a unique mode of modulatory interaction between monoamine and peptide in cortical circuits.

In summary, these findings provide electrophysiological evidence that VIP can alter inhibitory and excitatory somatosensory cortical neuronal responses to iontophoretically applied putative transmitters. This action of VIP could be of importance in understanding the precise function of this neuropeptide in cortical circuits and its involvement in various pathological conditions $(3,10)$. Our observations further suggest that VIP and NE can act together to alter the efficacy of local excitatory and inhibitory inputs to neocortical neurons. These findings support the hypothesis that the essentially perpendicular orientation of $\mathrm{NE}$ 
fibers and VIPergic neurons in the cerebral cortex may subserve a precise physiological function $(15,18)$. Specifically, NE and VIP afferents may exert convergent influences on cortical neuronal responses to afferent synaptic inputs such that modulatory actions are anatomically focused within the cortex. VIP neurons could then be part of a local mechanism whose function would be to regulate an otherwise global effect of NE on signal pro- cessing within neocortical circuits.

\section{ACKNOWLEDGEMENTS}

The authors wish to thank Dr. S. I. Said for his generous gift of VIP and Ms. Joy Hudson for typing the manuscript. This work was supported by grants AFOSR-87-0138, K04-NS01233, an award from the Klingenstein Foundation to B.D.W. and BRSG2-S07-RR07241 to F.M.S.

\section{REFERENCES}

1. Abens, J.; Westlind, A.; Bartfai, T. Chronic atropine treatment causes increase in VIP receptors in rat cerebral cortex. Peptides $5: 375-377 ; 1984$.

2. Besson, J.; Rotsztejn, W.; Poussin, B.; Lhiaubet, A. M.; Rosselin, G. Release of vasoactive intestinal peptide from rat brain slices by various depolarizing agents. Neurosci. Lett. 28:281-285; 1982.

3. Chee, C. A.; Roozendaal, B.; Swaab, D. F.; Goudsmit, E.; Mirmiran, M. Vasoactive intestinal polypeptide neuron changes in the senile rat suprachiasmatic nucleus. Neurobiol. Aging 9:307-312; 1988

4. Cheng, J-.T.; Sessler, F. M.; Azizi, S. A.; Chapin, J. K.; Waterhouse, B. D. Electrophysiological actions of norepinephrine in rat lateral hypothalamus. II. An in vitro study of the effects of iontophoretically applied norepinephrine on LH neuronal responses to gamma-aminobutyric acid (GABA). Brain Res. 446:90-105; 1988.

5. Eckenstein, F.; Baughman, R. W. Two types of cholinergic innervation in cortex, one co-localized with vasoactive intestinal polypeptide. Nature 309:153-155; 1984.

6. Ferron, A.; Siggins, G. R.; Bloom, F. E. Vasoactive intestinal polypeptide acts synergically with norepinephrine to depress sponataneous discharge rate in cerebral cortical neurons. Proc. Natl. Acad. Sci. USA 82:8810-8812; 1985.

7. Foehring, R. C.; Schwindt, P. C.; Crill, W. E. Norepinephrine selectively reduces slow $\mathrm{Ca}$ - and $\mathrm{Na}$-mediated $\mathrm{K}$ currents in cat neocortical neurons. J. Neurophysiol. 61:245-256; 1989.

8. Giachetti, A.; Said, S. I.; Reynolds, R. C.; Koniges, F. C. Vasoactive intestinal polypeptide in brain: Localization in and release from isolated nerve terminals. Proc. Natl. Acad. Sci. USA 74:3424-3428; 1977.

9. Haskins, J. T.; Samson, W. K.; Moss, R. L. Evidence for vasoactive intestinal polypeptide (VIP) altering the firing rate of preoptic, septal and midbrain central gray neurons. Regul. Pept. 3:113-123; 1982.

10. Kanamatsu, T.; Hirano, S. Differences in ME-LI and VIP-LI in discrete brain regions of seizure-naive and seizure-experienced EI mice. Neurochem. Res. 13:983-988; 1988.

11. Kirkness, E. F.; Bovenkerk, C. F.; Ueda, T.; Turner, A. J. Phosphorylation of gamma-aminobutyrate (GABA)/benzodiazepine receptors by cyclic AMP-dependent protein kinase. Biochem. J. 259: 613-616; 1989.

12. Lamour, Y.; Dutar, P.; Jobert, A. Effects of neuropeptides on rat cortical neurons: Laminar distribution and interaction with the effect of acetylcholine. Neuroscience 10:107-117; 1983.

13. Loren, I.; Emson, P. C.; Fahrenkrug, J.; Bjorklund, A.; Alumets, J.; Hakanson, R.; Sundler, F. Distribution of vasoactive intestinal polypeptide in the rat and mouse brain. Neuroscience 4:1953-1976; 1979.

14. Madison, D. V.; Nicoll, R. A. Noradrenaline blocks accommodation of pyramidal cell discharge in the hippocampus. Nature 299: $636-638 ; 1982$.

15. Magistretti, P. J.; Schorderet, M. VIP and noradrenaline act synergistically to increase cyclic AMP in cerebral cortex. Nature 308 $280-282 ; 1984$

16. Magistretti, P. J. Intercellular communication mediated by VIP in the cerebral cortex. Peptides 7:163-173; 1986.

17. Magistretti, P. J. VIP-containing neurons in the cerebral cortex: Cellular actions and interactions with the noradrenergic system. In
Ritchie, J. M.; Keynes, R. D.; Bolis, C. L., eds. Ionic channels in neural membranes. New York: Alan R. Liss; 1986:323-331.

18. Magistretti, P. J.; Morrison, J. H. Noradrenaline- and vasoactiveintestinal peptide-containing neuronal systems in neocortex: Functional convergence with contrasting morphology. Neuroscience 24 : 367-378; 1988.

19. Moises, H. C.; Woodward, D. J.; Hoffer, B. J.; Freedman, R. Interactions of norepinephrine with Purkinje cell responses to putative amino acid neurotransmitters applied by microiontophoresis. Exp. Neurol. 64:493-515; 1979.

20. Morrison, J. H.; Magistretti, P. J.; Benoit, R.; Bloom, F. E. The distribution and morphological characteristics of the intracortical VIP-positive cell: An immunohistochemical analysis. Brain Res. 292:269-282; 1984

21. Muly, E.; Lu, S. M.; Lin, C.-S. Vasoactive intestinal polypeptideimmunoreactive (VIP-IR) neurons in the rat somatosensory cortex. Soc. Neurosci. Abstr. 14:717; 1988.

22. Nicoll, R. A.; Malenka, R. C.; Kauer, J. A. Functional comparison of neurotransmitter receptor subtypes in mammalian central nervous system. Physiol. Rev. 70:513-532; 1990.

23. O'Dorisio, M. S. Biochemical characteristics of receptors for vasoactive intestinal polypeptide in nervous, endocrine, and immune systems. Fed. Proc. 46:192-195; 1987.

24. Phillis, J. W.; Kirkpatrick, J. R. Vasoactive intestinal polypeptide excitation of central neurons. Can. J. Physiol. Pharmacol. 56:337$340 ; 1978$.

25. Quik, M.; Iversen, L. L.; Bloom, S. R. Effect of vasoactive intestinal peptide (VIP) and other peptides on cAMP accumulation in rat brain. Biochem. Pharmacol. 27:2209-2213; 1978.

26. Said, S. I. Vasoactive intestinal peptide (VIP): Current status. Peptides 5:143-150; 1984.

27. Sessler, F. M.; Cheng, J-.T.; Waterhouse, B. D. Electrophysiological actions of norepinephrine in rat lateral hypothalamus. I. Norepinephrine-induced modulation of LH neuronal responsiveness to afferent synaptic inputs and putative neurotransmitters. Brain Res. 446:77$89 ; 1988$.

28. Sessler, F. M.; Mouradian, R. D.; Cheng, J-.T.; Yeh, H. H.; Liu, W.; Waterhouse, B. D. Noradrenergic potentiation of cerebellar Purkinje cell responses to GABA: Evidence for mediation through the beta adrenoceptor-coupled cyclic AMP system. Brain Res. 499: 27-38; 1989.

29. Taylor, D. P.; Pert, C. B. Vasoactive intestinal polypeptide: Specific binding to rat brain membranes. Proc. Natl. Acad. Sci. USA $76: 660-664 ; 1979$

30. Waterhouse, B. D.; Moises, H. C.; Woodward, D. J. Noradrenergic modulation of somatosensory cortical neuronal responses to iontophoretically applied putative neurotransmitters. Exp. Neurol. 69: $30-49 ; 1980$.

31. Waterhouse, B. D.; Moises, H. C.; Yeh, H. H.; Woodward, D. J. Norepinephrine enhancement of inhibitory synaptic mechanisms in cerebellum and cerebral cortex: Mediation by beta-adrenergic receptors. J. Pharmacol, Exp. Ther. 495:495-506; 1982.

32. Waterhouse, B. D.; Sessler, F. M.; Moises, H. C.; Grady, S. M. Neuropeptide modulation of somatosensory cortical neuronal responses to iontophoretically applied putative neurotransmitters. Soc. Neurosci. Abstr. 12; 1986. 